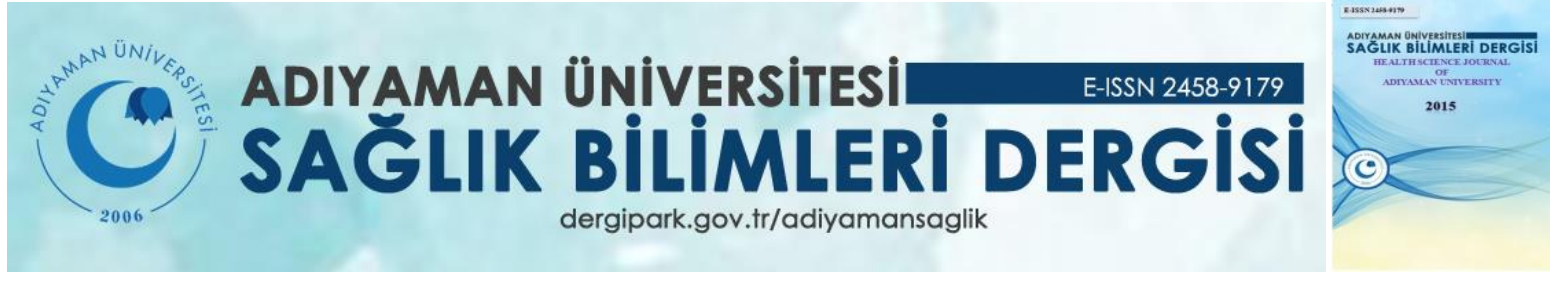

\title{
Araștırma/Research
}

\section{Çocuklarda Vezikoüreteral Reflü Tanısında Floroskopik Voiding Sistoüretrografi ile Voiding Ürosonografinin Karşılaştırılması \\ Selçuk UZUNER ${ }^{1}$, Gönül AYDOĞAN ${ }^{2}$, Sebuh KURUOĞLU ${ }^{3}$, PInar TURHAN ${ }^{4}$}

${ }^{1}$ Bezmialem Vakıf Üniversitesi, Tıp Fakültesi, Pediatri Anabilim Dalı, Fatih, İstanbul, Türkiye

${ }^{2}$ İstanbul Sağlık Bilimleri Üniversitesi Kanuni Sultan Süleyman Eğitim ve Araştırma Hastanesi, İstanbul, Türkiye ${ }^{3}$ İstanbul Üniversitesi Cerrahpaşa Tıp Fakültesi, İstanbul, Türkiye

${ }^{4}$ İstanbul Medeniyet Üniversitesi Göztepe Eğitim ve Araştırma Hastanesi, İstanbul, Türkiye

\section{$\ddot{O} \mathbf{z}$}

Amaç: Bu çalışmanın amacı, vezikoüreteral reflü yönünden ileri tetkik planlanan hastalarda voiding sistoüretrogram ve voiding ürosonografi yöntemlerinin reflünün ortaya konmasındaki başarı oranlarının değerlendirilmesidir.

Gereç ve Yöntemler: Çalışmaya vezikoüreteral reflü yönünden araştırılan ve voiding sistoüretrogram tetkiki planlanan 48 hasta alındı. Hastalar yaş, cinsiyet ve voiding sistoüretrogram planına neden olan nefrolojik problemler için değerlendirildi.

Bulgular: Çalışmadaki 48 hastanın 34'ü kız ve 14'ü erkekti. 48 hastanın 18'inde vezikoüreteral reflü saptandı. Tüm böbrek-üreter üniteleri vezikoüreteral reflü açısından değerlendirildi ve voiding sistoüretrogram ile \%91,3, voiding ürosonografi ile \%73,9 böbrek-üreter ünitesinde vezikoüreteral reflü tespit edildi. Kullanılan iki yöntemin tutarlılık oranı \%73,6 olarak saptandı. Grade I vezikoüreteral reflü olguları hariç tutulduğunda ise her iki yöntemin tutarlılık oranı \%87,6'dır. Vezikoüreteral reflü saptanması açısından her iki radyolojik yöntem arasında istatistiksel olarak anlamlı farkın olmadığg görüldü $(\mathrm{p}=0.146)$.

Sonuç: Seçilmiş olgularda voiding ürosonografi radyasyon yükü içermeyen alternatif bir tetkik olarak tercih edilebilir.

Anahtar Kelimeler: Vezikoüreteral reflü, voiding sistoüretrogram, voiding ürosonografi.

Bu çalışma "Çocuklarda Vezikoüreteral Reflü Tanısında Floroskopik Voiding Sistoüretrografi ile Voiding Ürosonografinin Karşılaştırılması”” 2005, başlıklı tez verilerinden elde edilmiştir.

\begin{tabular}{l}
\hline Yazışmadan Sorumlu Yazar \\
\hline Selçuk Uzuner \\
Bezmialem Vakıf Üniversitesi, Tıp Fakültesi, Pediatri \\
Anabilim Dalı, Fatih, İstanbul, Türkiye \\
Tel : +90 532694 4560 \\
Email: esuzuner@gmail.com \\
\hline
\end{tabular}

\section{Doi: 10.30569.adiyamansaglik.595298}

\begin{tabular}{ll}
\hline Geliş Tarihi: & 23.07.2019 \\
\hline Kabul Tarihi: & $\mathbf{0 8 . 0 8 . 2 0 1 9}$ \\
\hline
\end{tabular}


Comparison of Fluoroscopic Voiding Cystourethrography and Voiding Urosonography in the Diagnosis of Vesicoureteral Reflux in Children

\begin{abstract}
Purpose: The goal of the study was to investigate the success rates of voiding cystourethrogram and voiding urosonography in patients who were scheduled for further investigation vesicoureteral reflux.

Material and Methods: This study included 48 patients who were evaluated for vesicoureteral reflux and planned for voiding cystourethrogram. The patients were evaluated for gender, age and nephrologic problems which causing for plan voiding.

Results: Of the 48 patients in the study, 34 were female and 14 were male. Vesicoureteral reflux was detected in 18 of 48 patients. All renal-ureter units were evaluated for vesicoureteral reflux and $91.3 \%$ with voiding cystourethrogram and $73.9 \%$ with voiding urosonography were detected in the renal -ureter unit. The coherence rate of both methods was found to be $73.6 \%$ and it was shown that there was no statistically significant difference between the two methods for the detection of vesicoureteral reflux. When the cases of grade I vesicoureteral reflux were excluded from the study, the consistency rate of both methods increased to $87.6 \%$. There was no statistically significant difference between the methods for detecting vesicoureteral reflux in renal ureter units $(\mathrm{p}=0.146)$.
\end{abstract}

Conclusion: Voiding urosonography can be used as an alternative radiation-free imaging method for selected cases.

Key words: Vesicoureteral reflux, voiding cystourethrogram, voiding urosonography.

\title{
GíRiș
}

Çocuk nefroloji ve Çocuk cerrahi bilim dallarının sık karşılaşıtıları hastalıklardan birisi vezikoüreteral reflüdür (VUR). VUR; idrarın üreterovezikal bileşke yetersizliğine bağlı olarak mesaneden üretere doğru kaçışını tanımlamaktadır. Normal şartlarda üreterovezikal bileşke idrarın üreterden mesane içine girmesine (desanden akım) izin vermesine karşın, idrarın ters yönde üretere doğru kaçışına (asendan akım) izin vermez. Böylece özellikle işeme esnasında böbrekler mesane içindeki yüksek basınçtan korunduğu gibi enfekte olabilen mesane idrarıyla kontamine olmaktan da korunmuş olur. Bu kapakçık mekanizması yetersiz olduğunda üriner enfeksiyon gelişme olasıllğ̆ artar. Bu nedenle üriner sistem enfeksiyonu (ÜSE) ile VUR arasında çok güçlü bir ilişki mevcuttur. VUR tanısında gecikme veya yetersiz tedavi sonucunda tekrarlayan ÜSE’ler meydana gelebilir. Bunun sonucunda reflü ile birlikte nefropati, hipertansiyon, kronik böbrek yetersizliği (KBY) ve büyüme gelişme geriliği gibi geri dönüşü zor sağlık sorunları gelişebilmektedir. VUR önemli morbidite ve mortalite nedenidir. Batı ülkelerinde son dönem böbrek hastalığının (SDBH) etiyolojisinde \%5-12 oranında yer alan reflü nefropatisinin gelişmekte olan ülkelerde daha yüksek oranda SDBH'ye neden olduğu tahmin edilmektedir. Bu nedenle VUR'nin erken tanınması çok önemlidir (1-5). 
Kanıtlanmış ÜSE geçiren her çocuk VUR açısından değerlendirilmelidir. VUR tanısı için altın standart günümüzde "voiding sistoüretrogram (VCUG) kabul edilmektedir. VCUG; kontrast madde ve X-ışını kullanılarak dijital görüntülerin alındığı floroskopik bir radyolojik tetkiktir. Ancak bu tetkikin en önemli dezavantajı iyonize radyasyona maruziyet nedeniyle sinırlı kullanımıdır. İyonize radyasyon içermeyen "voiding ürosonografi (VUS)" VUR tanısında alternatif bir tetkik olarak bazı merkezlerde rutin kullanıma girmiştir (6-7). Çalışmamızda VUR yönünden araştırılan hastalarda "VCUG" ve "VUS" yöntemlerinin reflünün ortaya konmasındaki başarı oranlarının değerlendirilmesi amaçlanmıştır.

\section{GEREÇ ve YÖNTEMLER}

Çalışma grubunu SSK Bakırköy Doğumevi Kadın ve Çocuk Hastalıkları Eğitim Hastanesi Pediatrik Nefroloji Polikliniği'nden takipli VUR açısından araştırılan VCUG tetkiki endikasyonu koyulmuş 48 çocuk hasta oluşturdu. Çalışma, prospektif, randomize olmayan, standart test karşılaştırmalı olarak planlandı. Hastalar yaş, cinsiyet, VUR araştırılması endikasyonuna neden olan nefrolojik problemlerin dağılımı açısından sorgulandı ve radyoloji tarafından değerlendirilmek üzere form hazırlandı. Klinik çalışma, 1 Nisan 2004 ve 30 Ağustos 2004 tarihleri arasında İstanbul Üniversitesi Cerrahpaşa Tıp Fakültesi Radyoloji Anabilim Dalı'nda yapıldı. Hastaların tümüne VCUG ve VUS tetkikleri uygulanarak VUR araştırıldı. Çalışma için SSK Bakırköy Doğumevi Kadın ve Çocuk Hastalıkları Eğitim Hastanesi Etik Komitesi'nin onayı alındı. Her vaka için çalışma öncesi VCUG ve VUS'nin nasıl yapılacağı hakkında aileye yazılı ve sözlü bilgi verildi, ailenin yazılı onamı alındı. Hasta popülasyonunda çalışma öncesi genel durum iyiliği, normal hayati bulgular, idrar kültürünün steril olması ve idrarda redüktan maddenin negatif olması şartları arandı ayrıca hastalara uygun antibiyotik proflaksisi uygulandı. Her bir çalışma günü için bir hastaya randevu verildi, aynı gün içinde VCUG ve hemen sonrasında VUS tetkiki tamamlandı. Ağrılı ve invazif bir işlem olması nedeniyle mesane kateterizasyonu bir kez yapılacak şekilde çalışma düzeneği oluşturuldu. Çalışmada görev alan dört radyoloji hekimi VCUG çalışma grubu ve VUS çalışma grubu şeklinde iki eşit gruba ayrıldı. Grupların, çalışma ünitesi içinde birbirinden habersiz ve bağımsız çalışabilecekleri iki farklı ortam sağlandı. Hastalara midazolam etken maddesi içeren benzodiazepin preparatı olan Dormicum ${ }^{\circledR} 15 \mathrm{mg} / 3 \mathrm{ml}$ ampul (F. Hoffmann-La Roche Ltd, Basel, Switzerland) ile 0,2-0,3 $\mathrm{mg} / \mathrm{kg}$ dozunda intranazal yoldan bilinçli (bazal) sedasyon uyguland1. Mesane kateterizasyonu öncesi eksternal üretral mea ve çevresine 1lık steril su veya 
serum fizyolojikle ön temizliğin ardından alkol içermeyen, iritan olmayan uygun bir antiseptik solüsyon (Zefiran ${ }^{\circledR}$, Batticon ${ }^{\circledR}$ v.s) uygulandı. Tüm işlem basamaklarında asepsi-antisepsi kurallarına uyuldu. Lokal anestetik lidokain içeren cerrahi lubrikan (Cathejell@) ile kayganlaştırılan, “feeding” tüp ile (steril, tek kullanımlık, 6 numara, polivinil klorür nazogastrik kateter) transüretral yoldan mesane kateterize edildi varsa rezidü idrar boşaltıldı. İşlemler sırasında kolaylık sağladığı için feeding tüpün vücut dışında kalan proksimal kapaklı ucuna üçlü musluk takıldı. VCUG işlemi sonrası yerinde bırakılan katater üzerinden VUS işlemi de tamamlandı. Bu çalışmada VCUG için X-1şını kontrast maddesi olarak iyonik grupta yer alan, suda eriyebilen, iyot içerikli (370 mg I/ml), Urografin ${ }^{\circledR} \% 76$ (Schering AG, Berlin, Germany) kullanıldı. Kontrast madde steril şartlarda 1:2 oranında serum fizyolojik (SF) ile dilüe edilerek infüzyon sıvısı oluşturuldu. Oda 1sısında yeterli süre bekletilen infüzyon sıvısıyla hasta yatağından $70 \mathrm{~cm}$ yükseğe yerleştirilen setten damla infüzyonu ile feeding tüpteki üçlü musluk aracılığıyla boş mesane dolduruldu. Mesanenin dolumuna önceden hesaplanan tahmini mesane kapasitesi dikkate alınarak hastanın sözlü ifadesi, küçük çocukların vücut dili veya infüzyon sıvısının akımının yavaşlayıp durması ile karar verildi. Radyolojik görüntüleme Polystar ${ }^{\mathrm{TM}}$ Fluorospot H (Siemens, Erlangen, Germany) dijital floroskopi cihazı ile yapıldı. İnceleme sırasında grafi alınmadi. Görüntüler "Last Image Hold (LIH)" tekniği ile dondurulmuş floroskopik imajın, dijital alanda arşivlenmesi ile elde edildi. Grafi elde edilmeyip sadece skopi dozu ile görüntü alındığından ve tüm floroskopi süresi 0,1-0,4 dakika sürdüğünden maruz kalınan radyasyon dozu minimalize edildi. Ayrıca ALARA konsepti dikkate alınarak sadece incelenen alan üzerinde çalışıldı. Cihaz maksimum koruma programına alındı ve çocuk dozları kullanıldı. Üriner sistem mesane dolum fazı ve işeme fazında incelendi. Hastaların işeme öncesi mesane kateterleri çekilmedi, işemenin fizyolojik şartlara yakın olarak lümeni kapalı feeding tüp üzerinden (feeding tüple üretra arasında kalan boşluktan) aktif mesane kasılmalarıyla gerçekleşmesi sağlandı. Yerinde bırakılan feeding tüp sayesinde ideal çekimlerin başarılamadığı şüpheli durumlarda mesane tekrar doldurularak siklik VCUG uygulamaları yapılabildi ve ayrıca VUS öncesi tekrar mesane kateterizasyon ihtiyacı ortadan kalkmış oldu. Hastanın önce supine daha sonra sağ, sol ve oblik olarak tüm pozisyonlarda üriner sistemi incelendi.

Voiding sistoüretrogram işlemi sonrası hemen VUS işlemine geçildi. VUS için ultrason çalışmalarında Sonoline ${ }^{\mathrm{TM}}$ G60 S (Siemens, Erlangen, Germany) cihazının gri skala B-modu ve $500 \mathrm{MHz}$ konveks probu kullanıldı. Eko-kontrast madde olarak galaktoz bazlı mikro 
baloncuk (\%99'u $<12 \mu \mathrm{m}, \% 95$ 'i $<8 \mu \mathrm{m})$ sağlayan SH U 508 içeren Echovist-200® ultrason kontrast maddesi (Schering AG, Berlin, Germany) kullanıldı. Yine miktarı tahmini mesane kapasitesi dikkate alınarak hazırlanmış ve oda 1sısında yeterli süre bekletilmiş steril SF, feeding tüpteki üçlü musluk aracılığıyla boş mesaneye, hasta yatağından $70 \mathrm{~cm}$ yükseğe yerleştirilen setten damla infüzyonu ile verildi. VUS işlemindeki en kritik basamak olan eko-kontrast maddenin mesaneye verilişi yine feeding tüpteki üçlü musluğun boş olan diğer bir yolundan yapıldı ve SF ile dolmak üzere olan mesaneye hemen işeme öncesi steril şartlarda ve uygun miktarda Echovist-200® ultrason kontrast maddesi $(300 \mathrm{mg} / \mathrm{ml}$ konsantrasyonda eko-kontrast maddeden, mesaneyi dolduran SF miktarının hacmen 1/10'u kadar) verilerek mesane içindeki sıvının mikro baloncuklar sayesinde ultrasonografi (USG) ile görünebilirliği arttırıldı. VUR tanısı üst üriner sistemde, eko-kontrast madde verilişi sonrasında ve işeme süresince USG ile real-time mikro baloncuk görülmesiyle kondu. VCUG ve VUR sonuçları IRSC (International Reflux Study Committee) kriterlerine göre değerlendirildi Aşağıda IRSC reflü sınıflamasının açıklaması verilmiştir.

Grade I: Sadece dilate olmayan üretere reflü.

Grade II: Üreter, renal pelvis ve kalikslere kadar reflü. Ancak dilatasyon yok ve kaliks forniksleri normal. Grade III: Hafif orta derece dilate ve tortiöz üreter; hafif orta dilate renal pelvis. Ancak kaliks fornikslerinde küntleşme yok veya çok hafif.

Grade IV: Orta derece dilate ve tortiöz üreter, orta derece dilate pelvis ve kaliks fornikslerinde keskin açıların kaybı. Ancak kalikslerin çoğunda papiller görünüm korunmuş.

Grade V: Belirgin derece dilate ve tortiöz üreter, belirgin derece renal pelvis ve kalikslerin çoğunda papiller görünüm yok.(8).

\section{İstatistiksel Analiz}

Verilerin değerlendirilmesinde, SPSS 11.5 bilgisayar destekli paket programında elektronik ortama aktarılarak incelendi. Analizlerde sıklık dağılımlarının yanı sıra ortalama karşılaştırmalarında bağımlı gruplarda ki-kare testi kullanılmıştır. İstatistiksel anlamlılık düzeyi 0,05 olarak alınmıştır. Yöntemlerin uyumları için kappa katsayıları hesaplanıp ayrıca lambda simetri katsayısı ve kontenjans sayıları denetlenmiştir.

\section{BULGULAR}

Çalışmada değerlendirilen 48 hastanın 34'ü kız ve 14'ü erkekten oluşmaktaydı. Yaş ortalaması $85,5 \pm 56,4$ idi. Nefrolojik problemlerin dağılımı tablo 1 de verilmiştir. 
Tablo 1. Hasta grubunun özellikleri.

\begin{tabular}{|l|l|c|}
\hline & $\mathrm{n}$ & $\%$ \\
\hline Toplam hasta sayısı & 48 & - \\
\hline Hasta popülasyonunun yaş ort. (ay) & $85,5 \pm 56,4$ & - \\
\hline Kız/erkek oranı & $34 / 14$ & 72,9 \\
\hline ÜSE nedeniyle araştırılan hastalar & 35 & 8,3 \\
\hline İzlemdeki VUR hastaları & 4 & 4,1 \\
\hline Prenatal hidronefroz tanılı hastalar & 2 & 2,0 \\
\hline Böbrek transplantasyonu öncesi hastalar & 1 & 12,5 \\
\hline Enürezis nedeniyle araştırılan hastalar & 6 & \\
\hline
\end{tabular}

VUR açısından araştırılan 48 hastanın 93 böbrek-üreter ünitesinde (üç hastada tek böbrek mevcuttu) VCUG ve VUS sonuçları değerlendirildi. 48 hastanın $18^{\prime}$ inde $(\% 37,5)$ VUR saptandı. VCUG ile 11 vakada tek taraflı, 5 vakada çift taraflı VUR tanısı kondu. VUS ile 11 vaka tek taraflı, 3 vaka çift taraflı VUR tanısı aldı. VUR derecelerine göre sonuçlar değerlendirildiğinde 93 böbrek-üreter ünitesinde 7 grade I, 8 grade II, 5 grade III, 2 grade IV ve 1 grade V VUR saptand.

Toplam 93 böbrek-üreter ünitesinde VCUG ve VUS sonuçları incelendiğinde 23 böbrek-üreter ünitesinde $(\% 24,7)$ VUR saptand1. VUR tanıs1 alan böbrek-üreter üniteleri incelendiğinde VCUG ile 21/23 (\%91,3), VUS ile 17/23 (\%73,9) oranlarında VUR saptandı. VUR saptanan 23 böbrek-üreter ünitesinin 6'sı yalnız VCUG ile, 2'si yalnız VUS ile 15'i her iki tetkikle de tanı aldı. VCUG ve VUS'nin böbrek-üreter ünitelerinde VUR saptanmasındaki tutarlılık oranı (kappa katsayısı, к:0,736) \%73,6 bulundu. Böbrek-üreter ünitelerinde VUR saptanmas1 açısından her iki yöntem arasında istatistiksel olarak anlamlı fark saptanmadı $(p=0.146)$.

Grade I vezikoüreteral reflü olguları hariç tutulduğunda ise kalan 86 böbrek-üreter ünitesinin 16'sında $(\% 18,6)$ VUR saptand1. Grade I VUR dışında reflü tanısı alan 16 böbrek-üreter ünitesi incelendiğinde VCUG ile 15/16 (\%93,7), VUS ile 14/16 (\%87,5) böbrek-üreter ünitesinde VUR saptandı. Grade I vakaları hariç tutulduğunda her iki yöntemin VUR saptanmasındaki tutarlılık oranının (kappa katsayısı, к:0,876) \%87,6’ya yükseldiği görüldü. Yöntemler arasında VUR saptanması açısından istatistiksel anlamlı fark gözlenmedi $(\mathrm{p}=0.064)$.

Grade II ve üzeri VUR saptanan 16 böbrek-üreter ünitesinin 2'si yalnız VCUG ile, 1'i yalnız VUS ile 13'ü her iki tetkikle de tanı aldı. VUR tanısı alan 23 böbrek-üreter ünitesinde VCUG 
tetkikinin başarısı değerlendirildiğinde 21 böbrek-üreter ünitesinin tanı aldığı 2 böbrek-üreter ünitesinin atlandığı görüldü. VCUG tetkikinin duyarlılığ1 \%91,3; özgüllüğg̈ \%100 saptand1. Grade I VUR saptanan böbrek-üreter üniteleri hariç tutulduğunda VUR tanısı alan 16 böbreküreter ünitesinde VCUG tetkikinin başarısı değerlendirildiğinde 15 böbrek-üreter ünitesinin tanı aldığ1 1 böbrek-üreter ünitesinin atlandığı görüldü. VCUG tetkikinin duyarlılığı \%93,7; özgüllüğü \%100 olarak hesapland1. VUR tanısı alan 23 böbrek-üreter ünitesinde VUS tetkikinin başarısı değerlendirildiğinde, 17 böbrek-üreter ünitesinin tanı aldığı 6 böbrek-üreter ünitesinin atlandığ1 görüldü. VUS tetkikinin duyarlılığ $\% 73,9$ ve özgüllüğü \%100, yanlış negatif oranı $\% 26,1$ ve yanlış pozitif oranı $\% 0$, pozitif önerme değeri \%100 ve negatif önerme değeri \%92,1 olarak saptandı. VUS sonuçları ile gerçek sonuçlar arasında istatistiksel fark anlamlı değildi (p:0,41 McNemar testi). Grade I VUR saptanan böbrek-üreter üniteleri hariç tutulduğunda VUR tanısı alan 16 böbrek-üreter ünitesinde VUS tetkikinin başarısı değerlendirildiğinde 14 böbreküreter ünitesinin tanı aldığı 2 böbrek-üreter ünitesinin atlandığı görüldü. VUS tetkikinin duyarl11ığı \%87,5; özgüllüğü \%100 olarak hesapland1. Grade I VUR'nin hariç tutulduğu değerlendirmelerde tetkiklerin duyarlılıklarının arttığı gözlendi. Bu artış özellikle Grade I VUR tanısında yetersiz görünen VUS tetkikinde daha belirgindi. Yalnız VCUG ile VUR saptanan 6 böbrek-üreter ünitesinin 4'ü grade I VUR, 2'si grade II VUR tanısı aldı. Yalnız VUS ile tanı konan 2 böbrek-üreter ünitesinin 1'i grade I VUR, diğeri grade II VUR tanısı aldı.

Nefrolojik problemlerine göre gruplandırdığımız hastalarımızda VUR saptanma oranları şu şekilde bulundu: ÜSE nedeniyle araştırılan 35 hastadan 13'ünde VUR saptandı (\%37). VUR tanısıyla izlemde olan dört hastadan ikisinde (\%50), altı enürezisli olgunun birinde $(\% 16,7)$, iki prenatal hidronefroz saptanan hastanın her ikisinde (\%100) VUR saptand1. Renal transplantasyon adayı bir hastada ise VUR saptanmadı $(\% 0)$.

\section{TARTIŞMA}

Çocukluk çağı üriner sistem hastalıklarının başında VUR yer alır ve bu sistemin en sık görülen anatomik bozukluğudur (9). ÜSE tanısı alan çocuklarda VUR görülme sıklığının \%30-50, tekrarlayan ÜSE'li çocuklarda bu oranın ortalama \%35, ÜSE olmayan çocuklarda ise \%0,4-1,8 arasında olduğu bildirilmiştir (2,3). Rollestone'nun 350 süt çocuğunda yaptığ çalışmada vakaların \%42'sinde VUR saptamıştır. Bu vakaların 276'sı ÜSE nedeniyle, 74'ü ailede VUR hikayesi veya tek umblikal arter gibi enfeksiyon dişı nedenlerle araştırılmıştır (10). Bizim çalışmamızda ise vaka sayısı az olmakla birlikte ÜSE nedeniyle araştırılan 35 hastadan 13'ünde 
VUR saptandı (\%37). Özellikle gelişmiş ülkelerde VUR açısından ileri tetkikin yaygınlaşması ve VUR hastalarının yakın takibi ile reflü nefropatisi morbiditesinde belirgin azalma sağlanmıştır. Ancak gelişmekte olan ülkelerde reflü nefropatisi ve buna bağlı morbidite halen yüksek seyretmektedir $(8,11)$. Goldraich çalışmasında ÜSE nedeniyle araştırdığı ve VUR tanısı koyduğu 314 böbrekten 137'sinde (\%44) tanı anında reflü nefropatisi gelişmiş olduğunu bildirmiştir (12). Bizim çalışmamızda DMSA yapılan 25 ÜSE tanılı hastanın 11'inde (\%44) renal parenkimal skarla uyumlu sonuç bulunmuştur. Yine çalışmamızda ÜSE ve aynı zamanda VUR'si olan 11 hastada DMSA yapılmış yedi vakada $(\% 63,6)$ renal parenkimal skar saptanmıştır. Tanı anında skar oranlarının yüksekliği ülkemizde ÜSE ve VUR'nin önemli oranda atlandığını ve halen önemli bir sağlık sorunu olduğunu düşündürmektedir. İşlek ve arkadaşlarının ülkemizde yaptığı çalışmada KBY tanısıyla izlenen hastaların etyolojisi araştırılmış, 137 hastanın 24'ünde (\%17,5) etyolojinin reflü nefropatisi olduğu bildirilmiştir (13). Şirin ve arkadaşlarının yaptığı diğer çalışmada KBY tanısıyla izlenen 459 çocuğun 149'unda (\%32) reflü nefropatisine sekonder böbrek yetersizliği geliştiği saptanmıştır (14). Yapılan deneysel çalışmalar, VUR ve yüksek intravezikal basınç birlikteliğinin enfeksiyon olmadan da reflü nefropatisine yol açabildiğini göstermiştir (15). Yüksek morbidite ve mortalite nedeni olan VUR'nin tanısı önem taşımaktadır. Görüntüleme çalışmaları, ilk kez dökümente edilen ÜSE tanılı tüm erkek çocuklar, beş yaş altı kız çocuklar ve pyelonefrit geçiren veya reküren enfeksiyonu olan beş yaş üstü kız çocuklarda önerilmektedir (16). VUR teşhisinde VCUG yaygın olarak kullanılan ve altın standart kabul edilen bir tanı yöntemidir. Ancak VCUG'nin en önemli dezavantajı görece yüksek gonadal radyoaktivite ve intermitan görüntü alabilmesidir (6).

VUR genellikle mesane içi basınç belli bir seviyeye ulaştıktan sonra ortaya çıkar ve dolum fazının sonuna kadar VUR derecesinde artma görülebilir, reflü volümü intermitan olarak artıp azalabilir. Bazı vakalarda ise VUR mesane dolumu veya miksiyonun herhangi bir anında ortaya çıkabilir veya şiddeti değişebilir (17). Bu nedenle aynı seans içinde VCUG tekniğinde siklik görüntüleme çalışmaları gerekebilmektedir. Bu ek radyasyon yükü demektir. Üstelik VCUG çalışmaları, klinik pratikte VUR izleminde kümülatif radyasyon dozuna dikkat edilmeyerek kolay tekrarlanabilmektedir. Real-time görüntü alınabilen radyolojik yöntemlerden olan VUS, radyasyona maruziyeti ortadan kaldırdı̆̆ı için izlemdeki VUR hastalarında avantaj sağlayabilir. 
Literatürde VUR tanısında, VUS ve VCUG'nin etkinliğini karşılaştıran çalışmalar yer almaktadır. Papadopoulou ve arkadaşlarının yaptığı bir çalışmada, 463 böbrek-üreter ünitesinin 161 'inde VUR saptanmıştır. Bu çalışmada saptanan VUR'lerin, 90'1 sadece VUS ile 14'ü sadece VCUG ile tanı alırken 57'si her iki yöntemle de tanı almıştır. Her iki yöntem arasındaki fark anlamlı bulunmuş ve VUS'nin daha etkili bir yöntem olduğu sonucuna varılmıştır (18). Yine Kis ve arkadaşları, 366 böbrek-üreter ünitesinin 140’ında VUR saptamış ve yalnız VUS (37 ünite) ile yalnız VCUG’ye (14 ünite) göre daha fazla sayıda tanı konmuş ve VUS daha etkili bir yöntem olarak değerlendirilmiştir (19). Uhl ve arkadaşları ise 47 böbrek-üreter ünitesini değerlendirmiş ve 16'sı her iki yöntemle VUR tanısı alırken, 3'ü sadece VCUG ile tanı almış, VUS ile tek başına tanı alan saptanmamıştır (20). Yine Piskunowicz ve arkadaşlarının 2016 yılında yaptıkları bir diğer çalışmada da VUR saptanan 33/166 böbrek-üreter ünitesinde yöntemler arasından anlamlı bir farklılık saptanmamıştır ve VUS'nin VCUG'ye karşı seçilmiş olgularda alternatif olabileceği belirtilmiştir (21). Bizim çalışmamızda da VUR tanısında her iki yöntem arasında istatistiksel olarak anlamlı fark saptanmadı. Bu nedenle, kız çocukları, ameliyat sonrası antireflü cerrahi değerlendirilmesinde, izlemdeki yüksek grade VUR hastalarının takibi, kümülatif radyasyon yükü nedeniyle tekrarlayan VCUG uygulanmasının kontrendike olduğu durumlar gibi özellikli seçilmiş olgularda VUS'nin alternatif bir yöntem olarak değerlendirilebileceğini düşünmekteyiz.

\section{KAYNAKLAR}

1. Wallace DMA, Rothwell DL, Williams DI: The long term follow up of surgically treated vesicoureteral reflux. Br J Urol 1978; 50:479-84.

2. Burger RH, Smith C: Hereditary and familial vesicoureteral reflux. J Urol 1971; 106:845-51.

3. Ransley PG: Vesicoureteric reflux: Continuing surgical dilemma. Urology 1978; 12:246-55.

4. Jacobson SH, Eklof O, Eriksson CG, Lins LE, Tidgren B, Winberg J: Development of hypertension and uraemia after pyelonephritis in childhood: 27 year follow up. Br Med J 1989; 299:703-6.

5. Vallee JP, Vallee PD, Greenfield SP, Wan J, Springate J: Contemporary incidence of morbidity related to vesicoureteral reflux. Urology 1999; 53:812-5.

6. Sheldon CA, Wacksman J: Vesicoureteral reflux. Pediatr Rev 1995; 16:22-7.

7. Mentzel HJ, Vogt S, Patzer L, et al: Contrast-enhanced sonography of vesicoureterorenal reflux in children: Preliminary results. AJR Am J Roentgenol 1999; 173:737-40.

8. Report of the International Reflux Study Committee: Medical versus surgical treatment of primary vesicoureteral reflux. Pediatrics, 1981; 67:392-400. 
9. Kaefer M, Curran M, Treves ST, et al: Sibling vesicoureteral reflux in multiple gestation births. Pediatrics 2000; 105:800-4.

10. Rollestone GL, Shannon FT, Utley WLF: Follow up of vesico-ureteric reflux in the newborn. Kidney Int $1975 ; 8: 59-64$.

11. Yıldırım İ, Dayanç M: Vezikoüreteral reflü. In: Güncel Çocuk Ürolojisi (Dayanç M, ed.). Bölüm 8. Ankara: Atlas Kitapçılık, 2004: 145-88.

12. Goldraich NP, Goldraich IH: Follow up of conservatively treated children with high and low grade vesicoureteral reflux: A prospective study. J. Urol 1992; 148:1688-92.

13. İşlek İ: Çocukluk yaş grubu kronik böbrek yetmezliğinde etyolojik faktörler. Ondokuz Mayıs Üniversitesi Tıp Fakültesi Dergisi 1995; 12:113-20.

14. Şirin A, Emre S, Alpay H, Nayır A, Bilge İ, Tanman F: Etiology of chronic renal failure in Turkish children. Pediatr Nephrol 1995; 9:549-52.

15. Van den Abbeele AD, Treves ST, Lebowitz RL, et al: Vesicoureteral reflux in asymptomatic siblings of patient with known reflux: Radionuclide cystography. Pediatrics 1987; 79:147-53.

16. Sparrow MM. Nephrology. In: The Harriet Lane Handbook (Gunn VL, Nechyba C, ed), 16 th ed. Chapter 18.London: Mosby, 2002: 397-416.

17. Hodson CJ, Maling TMJ, McManamon PJ, Lewis MG: The pathogenesis of reflux nephropathy (chronic atrophic pyelonephritis). Br J Radiol Suppl 1975; 13:1-26.

18. Papadopoulou F, Anthopoulou A, Siomou E, Efremidis S, Tsamboulas C, Darge K. Harmonic voiding urosonography with a second-generation contrast agent for the diagnosis of vesicoureteral reflux. Pediatr Radiol. 2009 Mar;39(3):239-44.

19. Kis E, Nyitrai A, Várkonyi I, Máttyus I, Cseprekál O, Reusz G, Szabó A. Voiding urosonography with second-generation contrast agent versus voiding cystourethrography. Pediatr Nephrol. 2010 Nov;25(11):2289-93

20. Uhl M, Kromeier J, Zimmerhackl LB, Darge K. Simultaneous voiding cystourethrography and voiding urosonography. Acta Radiol. 2003 May;44(3):265-8.

21. Piskunowicz M, Świętoń D, Rybczyńska D, Czarniak P, Szarmach A, Kaszubowski M, Szurowska E. Comparison of voiding cystourethrography and urosonography with second-generation contrast agents in simultaneous prospective study. J Ultrason. 2016 Dec;16(67):339-347 